\title{
Validation of a simple hypoplastic constitutive model for overconsolidated clays
}

\author{
Shun Wang ${ }^{1}\left(\mathbb{D} \cdot\right.$ Wei $\mathrm{Wu}^{1}$
}

Received: 22 June 2020 / Accepted: 23 October 2020 / Published online: 19 November 2020

(C) The Author(s) 2020

\begin{abstract}
Hypoplastic constitutive models are able to describe history dependence using a single nonlinear tensorial function with a set of parameters. A hypoplastic model including a structure tensor for consolidation history was introduced in our previous paper (Wang and Wu in Acta Geotechnica, 2020, https://doi.org/10.1007/s11440-020-01000-z). The present paper focuses mainly on the model validation with experiments. This model is as simple as the modified Cam Clay model but with better performance. The model requires five parameters, which are easy to calibrate from standard laboratory tests. In particular, the model is capable of capturing the unloading behavior without introducing loading criteria. Numerical simulations of element tests and comparison with experiments show that the proposed model is able to reproduce the salient features of normally consolidated and overconsolidated clays.
\end{abstract}

Keywords Critical state $\cdot$ Hypoplastic model $\cdot$ Overconsolidation ratio $\cdot$ Structure tensor $\cdot$ Validation

\section{Introduction}

Overconsolidation is one of the most important factors that significantly influence the mechanical behavior of overconsolidated (OC) clays. Over the past decades, significant progress has been made in the development of constitutive models for predicting overconsolidation behavior of clays $[1,4,8,9,12,13,20,25,47-49]$. One of the main considerations for the evaluation of the models is that the model parameters can be easily obtained from conventional laboratory tests. For this purpose, firstly, the model parameters should possess clear physical meaning, and secondly, the model parameters should be independent of the initial states, such as the initial confining pressure and the initial overconsolidation ratio (OCR). Many elastoplastic models can properly describe the mechanical behavior of OC clays using a set of model parameters. However, model capacity is frequently gained at the sacrifice of simplicity.

Wei Wu

wei.wu@boku.ac.at

1 Institut für Geotechnik, Universität für Bodenkultur Wien, Feistmantelstrasse 4, 1180 Vienna, Austria
As an alternative to the prevailing plasticity theory, the hypoplastic models have gained much attention in the recent years [5-7, 15, 26-28, 30, 34-37, 39, 45]. Benefited from the nonlinear tensorial function, hypoplastic models are able to describe the overconsolidation behavior without resource to the concept in elastoplastic theory such as yield surface, plastic potential, differentiation between elastic and plastic behaviors, and loading criterion [38, 41-44]. Therefore, compared to the elastoplastic models, hypoplastic models are usually characterized by simpler formulations and fewer model parameters. Consequently, the numerical implementation of hypoplastic models is quite straightforward.

Hypoplastic models were originally developed for granular materials, and most applications of hypoplastic models focused on the simulation of sands. There are a number of hypoplastic models for clays. For instances, a series of hypoplastic models for fine-grained soils were proposed by Mašín $[16,18,19]$. These models open a new avenue for modeling of OC clays. Based on these models, some extensions for OC clays were made by Shi et al. [33] and Wang et al. [39]. Whereas the aforementioned models provide a fairly decent prediction for OC clays, their formulations are rather intricate and further extensions based on these models will inevitably increase the complexity of 
the model and the number of the parameters. A hypoplastic model possessing simple formulations and fewer parameters is therefore pressing to benefit the development of more sophisticated models for clays.

This paper follows the line of our previous work [38], in which a general hypoplastic framework for OC soils was outlined. A structure tensor was included in a hypoplastic model to account for the consolidation history of soils. The theory and performance of the model were however presented based on a basic hypoplastic model for granular materials [44]. Hence, the model adopts a set of material parameters for sand, which might be unsuitable for clay. In the present paper, the parameters of the basic hypoplastic model are calibrated for clays. This leads to a reduction of the constitutive parameters, which are easy to calibrate from conventional laboratory experiments. Moreover, the Matsuoka-Nakai failure criterion is included in the new model. The influence of model parameters on the model prediction is analyzed by performing a series of elementary tests. In the end, the model is validated by comparing the numerical predictions with experiments on different OC clays.

\section{Hypoplastic constitutive model for OC clays}

\subsection{General framework}

Let us consider the following hypoplastic constitutive model proposed by $\mathrm{Wu}$ and Kolymbas [40]:

$$
\stackrel{\circ}{\mathbf{T}}=\mathcal{L}: \mathbf{D}+\mathbf{N}\|\mathbf{D}\|
$$

where $\mathcal{L}$ and $\mathbf{N}$ are fourth- and second-order tensorial functions, respectively. The colon : denotes an inner product between two tensors. $\mathbf{D}$ is the strain rate (stretching) tensor, and $\|\mathbf{D}\|=\sqrt{\operatorname{tr}\left(\mathbf{D}^{2}\right)}$ stands for the norm of the strain rate tensor. $\stackrel{\circ}{\mathbf{T}}$ is the Jaumann stress rate defined as follows:

$\stackrel{\circ}{\mathbf{T}}=\dot{\mathbf{T}}+\mathbf{T W}-\mathbf{W T}$

where $\mathbf{T}$ and and $\dot{\mathbf{T}}$ are the Cauchy stress tensor and the material time derivative of the Cauchy stress, respectively; $\mathbf{W}$ is the spin tensor.

In order to describe the overconsolidation behavior using hypoplasticity, Wang and $\mathrm{Wu}$ [38] introduced a structure tensor to account for history dependence in the following way:

$\stackrel{\circ}{\mathbf{T}}=\mathcal{L}(\mathbf{T}+\mathbf{S}): \mathbf{D}+\mathbf{N}(\mathbf{T}-\mathbf{S})\|\mathbf{D}\|$

where $\mathbf{S}$ is a structure tensor representing the overconsolidation. The following simple expression is used for the structure tensor:

$$
\mathbf{S}=\alpha \ln \left(\frac{1}{R}\right) \mathbf{T}
$$

where $\alpha$ is a model parameter, which controls the influence of the consolidation history; and $R$ is a stress ratio representing the degree of overconsolidation with a smaller value of $R$ corresponding to a larger OCR. It reads

$R=\frac{p_{e}^{+}}{p_{e}}$

in which $p_{e}^{+}$and $p_{e}$ are the preconsolidation pressure in the modified Cam Clay (MCC) model and the Hvorslev equivalent pressure, respectively. Their formulations are given as follows:

$p_{e}^{+}=p\left[1+\left(\frac{q}{M p}\right)^{2}\right]$ and $p_{e}=\exp \left[\frac{N-\ln (1+e)}{\lambda^{*}}\right]$

where $p$ and $q$ are the mean stress and deviatoric stress, respectively; the inclination $M$ corresponds to the stress ratio at the critical state; $e$ is the current void ratio; the index $\lambda^{*}$ is the slope of the normal compression line in the double logarithmic $\ln (1+e)-\ln p$ plane; $N$ denotes the logarithmic value of the specific volume at the reference stress $p_{r}=1 \mathrm{kPa}$. Note that the parameter $N$ is different from the tensorial function $\mathbf{N}$ in Eq. (1).

In addition to the structure tensor, an additional multiplier $f_{u}$ is introduced to improve the model performance for isochoric strain rate, giving

$\stackrel{\circ}{\mathbf{T}}=\mathcal{L}(\mathbf{T}+\mathbf{S}): \mathbf{D}+f_{u} \mathbf{N}(\mathbf{T}-\mathbf{S})\|\mathbf{D}\|$

in which the multiplier $f_{u}$ is defined as

$f_{u}=\frac{\|\mathbf{B}: \mathbf{D}\|}{\|\mathbf{B}\|\|\mathbf{D}\|}$

where $\mathbf{B}=-\mathcal{L}^{-1}: \mathbf{N}$ denotes the flow rule of the model. One may refer to [38] for the mechanism of the function $f_{u}$ on the improvement of undrained triaxial tests.

\subsection{Hypoplastic equation}

With the framework incorporating consolidation history, we proceed to consider the following specific constitutive model, which is rearranged from a basic hypoplastic model proposed by Wu et al. [44]:

$$
\stackrel{\circ}{\mathbf{T}}=f_{s}\left[(\operatorname{tr} \mathbf{T}) \mathbf{D}+f_{v}(\operatorname{tr} \mathbf{D}) \mathbf{T}+a^{2} \frac{\operatorname{tr}(\mathbf{T D})}{\operatorname{tr} \mathbf{T}} \mathbf{T}+a\left(\mathbf{T}+\mathbf{T}^{*}\right)\|\mathbf{D}\|\right]
$$


where $\mathbf{T}^{*}$ is the deviatoric part of $\mathbf{T} ; f_{s}$ is the stiffness factor and $f_{v}$ is a multiplier influencing the volumetric response of the model; the material constant $a$ corresponds to the limit stress at the critical state. The definition of $a$ including the Matsuoka-Nakai failure criterion will be given in Section 2.4.

Combining Eqs. (7) and (9), we obtain the following simple hypoplastic model:

$$
\begin{aligned}
\stackrel{\circ}{\mathbf{T}}= & f_{s}\left[(\operatorname{tr} \check{\mathbf{T}}) \mathbf{D}+f_{v}(\operatorname{tr} \mathbf{D}) \check{\mathbf{T}}+a^{2} \frac{\operatorname{tr}(\check{\mathbf{T}} \mathbf{D})}{\operatorname{tr} \check{\mathbf{T}}} \check{\mathbf{T}}\right. \\
& \left.+f_{u} a\left(\hat{\mathbf{T}}+\hat{\mathbf{T}}^{*}\right)\|\mathbf{D}\|\right]
\end{aligned}
$$

where $\check{\mathbf{T}}=\mathbf{T}+\mathbf{S}$ and $\quad \hat{\mathbf{T}}=\mathbf{T}-\mathbf{S}$ are adopted for simplicity.

The constitutive model (9) was originally developed for sand. For modeling the OC behavior of clays, the stiffness factor $f_{s}$ and the multiplier $f_{v}$ should be calibrated to allow this model to describe the stiffness and volumetric response of OC clays. These multipliers can be related to some widely used parameters in soil mechanics. In the following, we proceed to determine $f_{s}$ and $f_{v}$ for OC clays. The complete formulation of constitutive model (10) is given in Appendix A.

\subsection{Calibration of $f_{v}$ and $f_{s}$}

Bearing in mind that normal consolidation with $\mathrm{ORC}=1$ leads to $R=1$, and thus, the structure tensor vanishes with $\mathbf{S}=\mathbf{0}$. This implies $f_{s}$ and $f_{v}$ can be determined by using the so-called consistency assumption [2, 16], i.e., isotropically compressing a soil sample from its normal consolidation state. To this end, we turn our attention to the model (9) and write out the decomposed formulations as follows:

$$
\begin{aligned}
-\dot{p}= & p f_{s}\left[\left(1+\frac{a^{2}}{3}+f_{v}\right) \mathrm{D}_{v}\right. \\
& \left.+a^{2} \hat{q} \mathrm{D}_{q}+a \sqrt{\frac{\mathrm{D}_{v}^{2}}{3}+\frac{3}{2} \mathrm{D}_{q}^{2}}\right] \\
\dot{q}=3 p f_{s} & {\left[\frac{3}{2} \mathrm{D}_{q}+\left(\frac{a^{2}}{3}+f_{v}\right) \mathrm{D}_{v} \hat{q}+a^{2} \hat{q} \mathrm{D}_{q} \hat{q}\right.} \\
& \left.+2 \hat{q} a \sqrt{\frac{\mathrm{D}_{v}^{2}}{3}+\frac{3}{2} \mathrm{D}_{q}^{2}}\right]
\end{aligned}
$$

where $\dot{p}$ and $\dot{q}$ are the rates of the mean stress $p$ and deviatoric stress $q$, respectively; $\hat{q}=q / \operatorname{tr} \mathbf{T}$ is the normalized deviatoric stress; $D_{v}$ and $D_{q}$ stand for the volumetric and deviatoric strain rates, respectively.
First, we consider the stiffness factor $f_{s}$ for a normally consolidated clay. Following the work by Butterfield [3], the rate of the mean stress $\dot{p}$ can be expressed as follows:

$\dot{p}=\frac{-p \dot{e}}{\lambda^{*}(1+e)}$

where $\dot{e}$ denotes the rate of the current void ratio.

Note that the constitutive model (10) should predict the same $\dot{p}$ for an isotropic compression tests. To this end, let us recall the $\dot{p}$ expressed in Eq. (11a). Initially, we have $D_{q}=0$ and $D_{v}=\dot{e} /(1+e)<0$, thus Eq. (11a) becomes

$\dot{p}=\frac{p f_{s} \dot{e}}{(1+e)}\left(1+\frac{1}{3} a^{2}+f_{v}-\frac{\sqrt{3}}{3} a\right)$

Comparison between Eqs. (12) and (13) yields a general form for $f_{s}$ :

$f_{s}=-\frac{1}{\lambda^{*}}\left(1+\frac{1}{3} a^{2}+f_{v}-\frac{\sqrt{3}}{3} a\right)^{-1}$

Next, we confine our attention to the multiplier $f_{v}$. Analogously, Eq. (11a) is able to predict the initial bulk modulus of a soil in the following way:

$-\dot{p}=p f_{s}\left(1+\frac{1}{3} a^{2}+f_{v}-\frac{\sqrt{3}}{3} a\right) \mathrm{D}_{v} \triangleq K_{i} \mathrm{D}_{v}$

where $K_{i}=p f_{s}\left(1+a^{2} / 3+f_{v}-\sqrt{3} / 3 a\right)$ represents the initial bulk modulus of a sample in an isotropic compression test.

On the other hand, in an undrained test with constant volume, i.e., $D_{v} \equiv 0$, Eq. (11b) is recast to

$\dot{q}_{i}=\left.\dot{q}\right|_{\hat{q}=0}=\frac{9}{2} f_{s} p \mathrm{D}_{q} \triangleq 3 G_{i} \mathrm{D}_{q}$

in which $G_{i}=1.5 p f_{s}$ denotes the initial shear stiffness at an isotropic stress state.

As assumed in previous works [10, 11, 16, 39], the ratio $v_{i}=K_{i} / G_{i}$ can be considered as a material constant, which has a similar physical meaning to Poisson's ratio. As a consequence, a simple formulation for the multiplier $f_{v}$ is obtained as follows:

$f_{v}=\frac{3}{2} v_{i}-\frac{1}{3}\left(3+a^{2}-\sqrt{3} a\right)$

Accordingly, the stiffness factor $f_{s}$ is obtained by substituting Eq. (17) into Eq. (14):

$f_{s}=-\frac{2}{3 v_{i} \lambda^{*}}$

It is worth noting that the formulations of $f_{s}$ and $f_{v}$ for clays contain both the deformation parameters $\left(v_{i}\right.$ and $\left.\lambda^{*}\right)$ and the strength parameter $\left(a\right.$ or $\left.\phi_{c}\right)$ through simple formulations. 


\subsection{Failure criterion}

Equation (1) describes a critical state condition for continuing deformation when the directional stiffness vanishes, then we have $\stackrel{\circ}{\mathbf{T}}=\mathbf{0}$, which corresponds to

$\mathbf{B}=-\mathcal{L}^{-1}: \mathbf{N}=\frac{\mathbf{D}}{\|\mathbf{D}\|}$

Taking the norm of both sides gives rise to the failure criterion at the critical state.

$f=\|\mathbf{B}\|-1=0$

At the critical state, the model (10) degrades to (9) with $\mathbf{S}=$ $\mathbf{0}$ and $f_{u}=1$, indicating the same failure criterion for the two models. To obtain the failure criterion, we can write out the explicit expression of $\mathbf{B}$ for model (9):

$\mathbf{B}=\frac{a}{\operatorname{tr} \mathbf{T}}\left[\mathbf{T}^{*}+\mathbf{T} \frac{(\operatorname{tr} \mathbf{T})^{2}-a^{2}\left\|\mathbf{T}^{*}\right\|^{2}}{\left(1+f_{v}\right)(\operatorname{tr} \mathbf{T})^{2}+a^{2}\|\mathbf{T}\|^{2}}\right]$

With the above equation, the failure condition (20) is equivalent to

$f=a\left\|\mathbf{T}_{c}^{*}\right\|-\operatorname{tr} \mathbf{T}_{c}=0$

where the $\mathbf{T}_{c}$ and $\mathbf{T}_{c}^{*}$ denote the stress tensor at the critical state and its deviatoric part, respectively. Obviously, the parameter $a$ in Eq. (22) is related to the critical state value of the normalized deviatoric stress $\left\|\mathbf{T}_{c}^{*}\right\| / \operatorname{tr} \mathbf{T}_{c}$. With a constant value for $a$, Eq. (22) has a conical shape in the principal stress space, which resembles that of the DruckerPrager failure surface $[36,44]$. In order to describe the soil behavior under true triaxial condition, the following formula is adopted for $a$ :

$a=\frac{\sqrt{3} \eta\left(3-\sin \phi_{c}\right)}{2 \sqrt{2} \sin \phi_{c}}$

where $\phi_{c}$ is the critical state friction angle of the material; the factor $\eta$ is adopted to incorporate the Matsuoka-Nakai failure criterion according to Yao et al. [46]. It reads

$$
\eta=\frac{2 I_{1}}{3 \sqrt{\left(I_{1} I_{2}-I_{3}\right)\left(I_{1}^{2}-3 I_{2}\right) /\left(1_{1} I_{2}-9 I_{3}\right)}-\sqrt{\left(I_{1}^{2}-3 I_{2}\right)}}
$$

in which $I_{1}, I_{2}$, and $I_{3}$ are stress invariants. It should be noted that a weighted factor can be applied on $\eta$ to smoothly change the failure criterion from the DruckerPrager to the Matsuoka-Nakai criterion. More details can be found in the reference [46].

\section{Model parameters}

\subsection{Summary of model parameters}

The proposed hypoplastic model contains five parameters, i.e., $\phi_{c}, \lambda^{*}, N, v_{i}$, and $\alpha$. The first three have the same physical meaning as those used in the MCC model: $\phi_{c}$ is the critical state friction angle; $\lambda^{*}$ is the slope of the isotropic normal compression line in the double logarithmic plane $\ln (1+e)-\ln p ; N$ is the value of $\ln (1+e)$ at the isotropic normal compression line for $p_{r}=1 \mathrm{kPa}$; and the parameter $v_{i}$ is the ratio of the bulk modulus in the isotropic compression and the shear modulus in the undrained shear test on the isotropic consolidated sample; it has a similar physical meaning to Poisson's ratio. Finally, the additional parameter $\alpha$ controls the magnitude of the structure tensor.

Overall, the parameters $\lambda^{*}$ and $N$ can be determined from an isotropic consolidation test. The parameters $\phi_{c}$ and $v_{i}$ can be determined either from a triaxial compression tests with constant mean stress or a conventional triaxial compression test. Therefore, only the determination of the parameter $\alpha$ requires curve fitting, and the other parameters can be measured in a straightforward way.

\subsection{Effects of model parameters on model predictions}

The model parameters $\lambda^{*}, N$, and $\phi_{c}$ are the same with those used in the MCC model [31, 32]. In the following, therefore, a parametric study considering only $\alpha$ and $v_{i}$ is performed. Several triaxial compression tests are modeled to show the influences of $\alpha$ and $v_{i}$ on the model prediction. For this purpose, the parameters $\phi_{c}=20^{\circ}, \lambda^{*}=0.05$, and $N=1.0$ are fixed, while $\alpha$ and $v_{i}$ vary in a certain range. The confining pressure is assumed to be $100 \mathrm{kPa}$. Three different OCRs $(5,2.5$, and 1.2) are considered in drained and undrained conditions.

Figure 1a and $\mathrm{c}$ show the stress-strain relation of drained and undrained tests. It can be seen that a greater $\alpha$ leads to a larger initial stiffness. Consequently, steeper stress-strain curves are obtained in the simulations. For heavy overconsolidation, i.e., OCR $=5$, the increase of $\alpha$ will also gives rise to an enhancement of the peak shear strength. Meanwhile, more dilatant volumetric responses are observed at the onset of drained tests, as shown in Fig. 1b. The normalized effective stress paths under undrained condition are shown in Fig. 1d. Obviously, the effective stress paths move to the right with the increase of $\alpha$, indicating the decrease of the excess pore pressure. Nevertheless, $\alpha$ does not influence the model prediction at critical state. The above analysis shows that $\alpha$ mainly influences the initial stiffness of OC clays, and it can be 


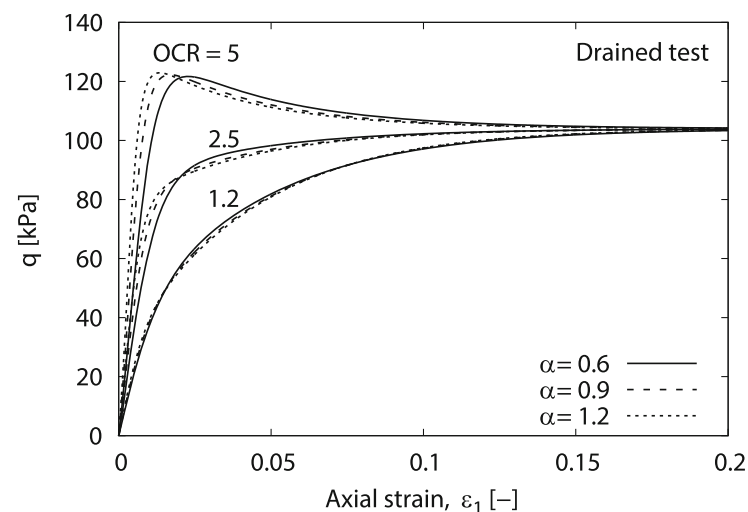

(a)

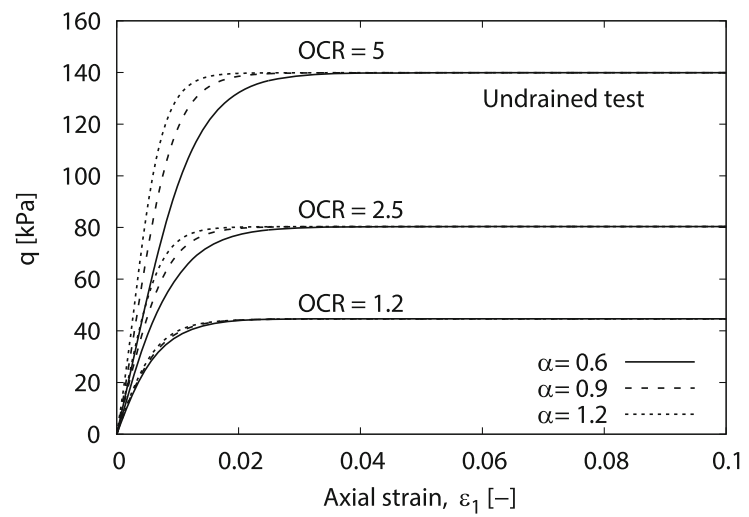

(c)

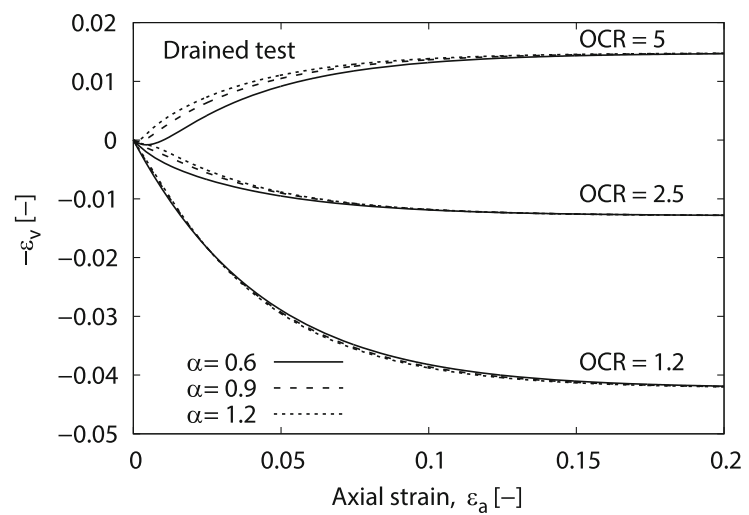

(b)

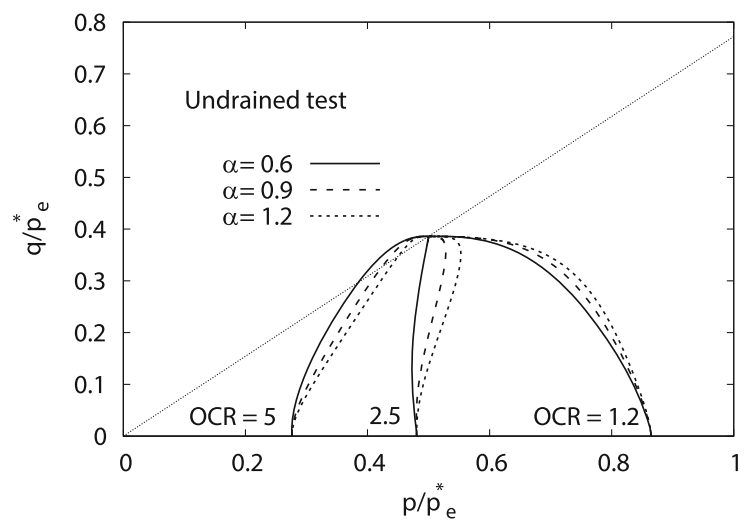

(d)

Fig. 1 Influence of the parameter $\alpha$ on model prediction in drained and undrained triaxial compression tests

also used to adjust the peak shear strength for heavy overconsolidation in drained simulations.

The same numerical tests are performed to show the effects of parameter $v_{i}$ on the model prediction. The results are plotted on the planes $\varepsilon_{1}-q$ and $p / p_{e}^{*}-q / p_{e}^{*}$. Figure $2 \mathrm{a}$ and $\mathrm{c}$ shows the stress-strain relation of drained and undrained tests. As indicted by Eq. (18), the parameter $v_{i}$ influences the stiffness multiplier $f_{s}$. Increasing of $v_{i}$ gives rise to the decrease of $f_{s}$ and eventually leads to softer stiffness responses. Figure $2 \mathrm{~b}$ and $\mathrm{d}$ shows the normalized effective stress paths under drained and undrained conditions. For both conditions, the effective stress paths move to the left with the increase of $v_{i}$. The change of effective stress path, however, becomes less significant with the increase of the OCR. The simulations reveal that the parameter $v_{i}$ mainly affects the stiffness response of OC clays.

\section{Validation with experimental results}

In this section, the model predictions are compared with experimental results of different fine-grained soils, namely Fujinomori clay [21, 22], Lower Cromer till [29], and Boston blue clay [29]. Different tests are simulated to validate the proposed model. The model parameters for different soils are summarized in Table 1. The first three parameters are collected from the literature, while the parameters $v_{i}$ and $\alpha$ are obtained through optimization methods $[50,51]$ to gain the best match with experimental data.

\subsection{Fujinomori clay}

First, let us inspect the prediction of drained and undrained triaxial tests on normally consolidated Fujinomori clay. The test results were used to calibrate several hypoplastic models [11, 17] and elastoplastic models [14, 23, 47]. In the simulations, the initial state $p_{0}=196 \mathrm{kPa}$ and $e_{0}=$ 0.915 is considered. The parameters $\phi_{c}, \lambda^{*}$, and $N$ listed in Table 1 are similar to those used in the literature [17]. 


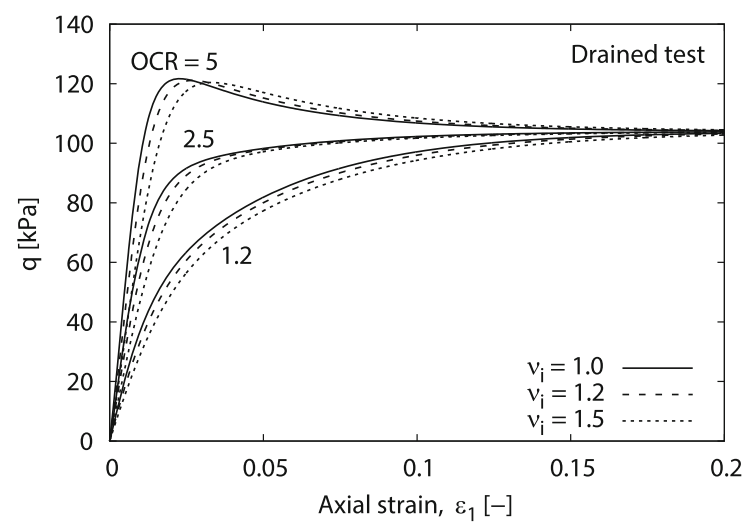

(a)

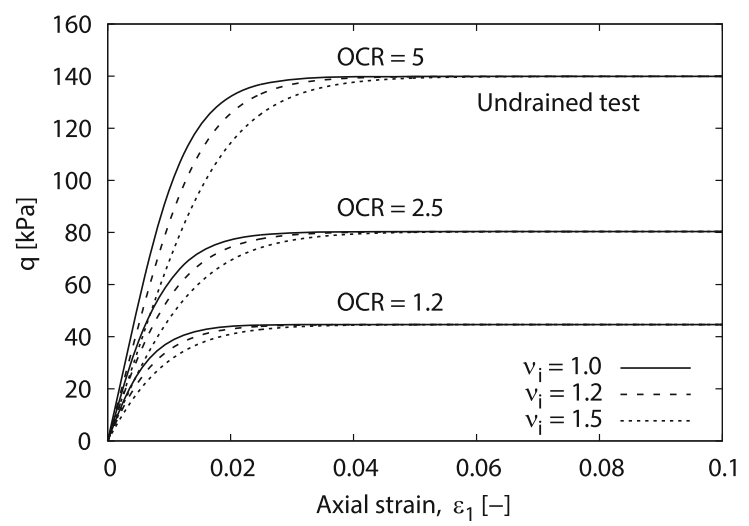

(c)

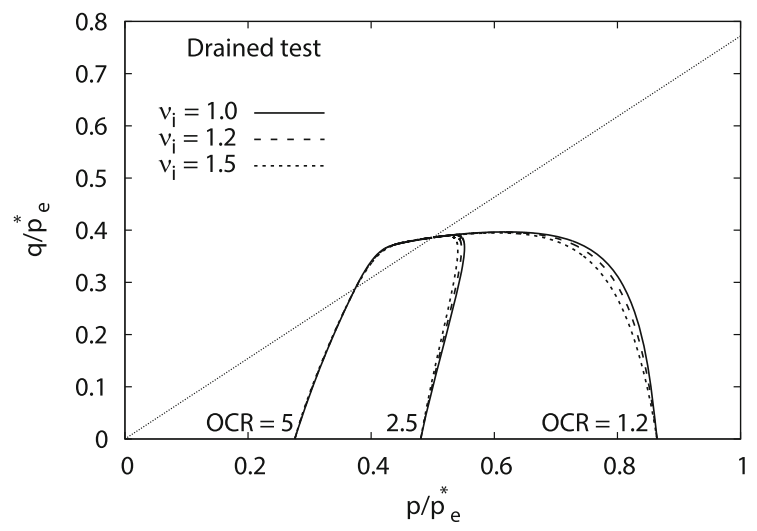

(b)

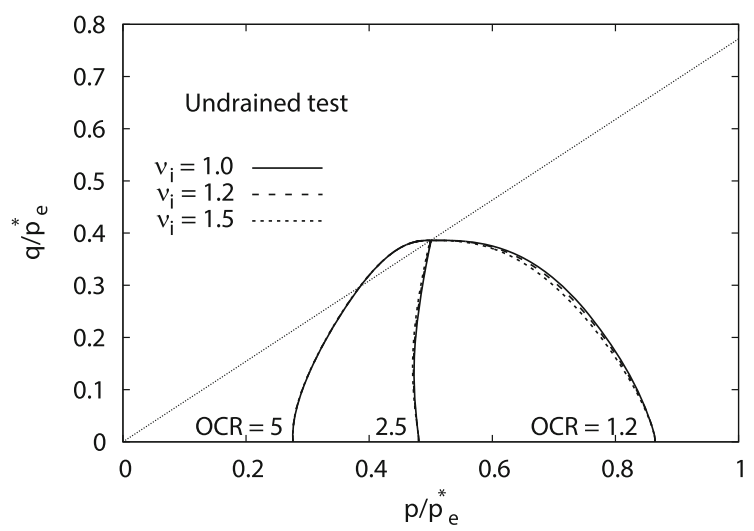

(d)

Fig. 2 Influence of the parameter $v_{i}$ on model prediction in drained and undrained triaxial compression tests

Table 1 Model parameters for simulation of different clays

\begin{tabular}{llllll}
\hline Soils & $\phi_{c} /^{\circ}$ & $\lambda^{*}$ & $N$ & $v_{i}$ & $\alpha$ \\
\hline Fujinomory clay & 33.7 & 0.0445 & 0.88 & 0.6 & 0.4 \\
Lower Cromer till & 30.0 & 0.047 & $0.62(0.61)$ & 0.8 & 1.0 \\
Boston blue clay & 33.5 & 0.025 & 0.815 & 1.0 & 0.3 \\
\hline
\end{tabular}

Details for the properties of Fujinomori clay can be found in [21].

Figure 3 shows the comparison between numerical and experimental results of drained triaxial tests. These results are shown in terms of the normalized deviatoric stress and volumetric strain against the axial strain. The numerical predictions reproduce well the observed soil behavior, except that a more contractive volume change is obtained at the vicinity of shearing.

A further concern of the proposed model lies in the capacity of modeling undrained loading. In the simulation of undrained compression tests, the same initial state as that used in the drained compression test is considered. The comparison between predictions and experiments is shown in Figure 4. It can be seen that the proposed model predicts correctly the deviatoric stress, the stress path, as well as the variation of the axial and radial effective stresses with respect to the deviatoric strain.

The next simulation is concerned with the prediction of overconsolidation behavior. To this end, a set of drained triaxial tests with constant mean stress on OC Fujinomori clay are performed. The initial OCRs are between 1 and 8 . The specimen with initial OCR $=8$ was tested at a mean effective stress of $p_{0}=98 \mathrm{kPa}$, while other specimens were tested at mean effective stress of $196 \mathrm{kPa}$. The initial void ratios for $\mathrm{OCR}=2,4$, and 8 are $e_{0}=0.863,0.833$, and 0.857 , respectively. The predicted stress-strain and volumetric change curves using the proposed model are shown in Figure 5. An excellent agreement in the stress ratio curves is achieved in the compression tests. More obvious difference between predictions and experimental results is observed in the volumetric strain. Specifically, the model underestimates the dilatancy of the Fujinomori clay at OCR $=2$ and 4. At these OCRs, a larger contractive volume changes are predicted by the model. Nevertheless, the main features of the variation of stress ratio and volumetric strain can be reasonably captured by the proposed model. 


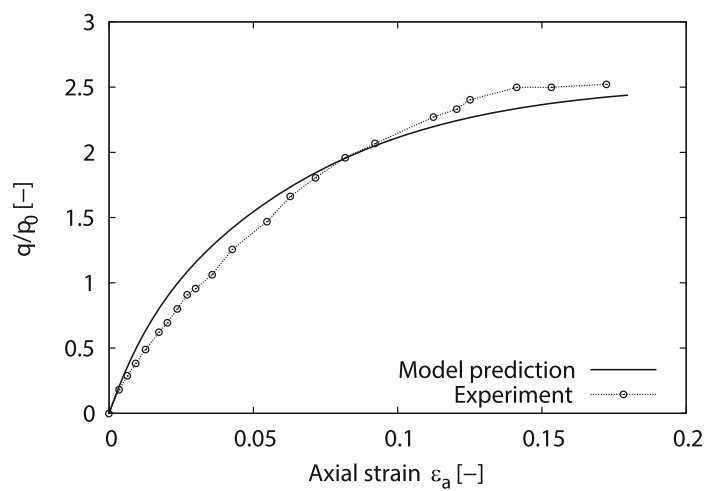

(a)

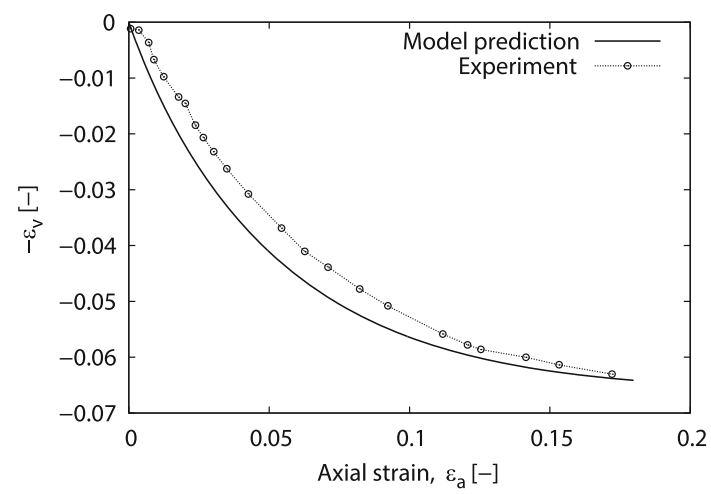

(b)

Fig. 3 Comparison between experimental and numerical drained triaxial tests on normally consolidated Fujinomory clay. Experimental data from Nakai and Mihara [21]

\subsection{Lower Cromer till}

The next simulation will focus on illustrating model capabilities to describe the overconsolidation behavior in standard drained triaxial compression tests. The soil, Lower Cromer till, is classified as a low plasticity sandy silty-clay with a clay fraction of approximately $17 \%$ [29]. Several drained triaxial compression tests are performed using the parameters listed in Table 1. Except $v_{i}$ and $\alpha$, all the other parameters can be obtained from experiments given in [29].

First, normal compression tests (both hydrostatic and $K_{0}$ compression conditions) with loading and unloading are simulated. Note that two different values for the material constant $N$ are used in the isotropic compression test and the oedometer test. Figure 6 shows the predictions together with experimental results. The behavior of Lower Cromer Till in both hydrostatic and $K_{0}$ conditions is well described by a linear normal compression line in the $e-\ln p$ plane. The predicted normal compression lines agree well with the experiments because the stiffness factor $f_{s}$ of the proposed model ensures to predict the predefined normal compression line. In particular, an excellent agreement in

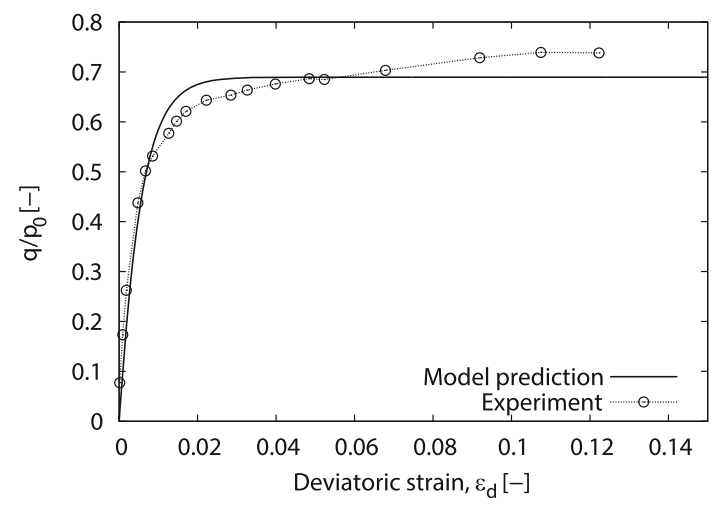

(a)

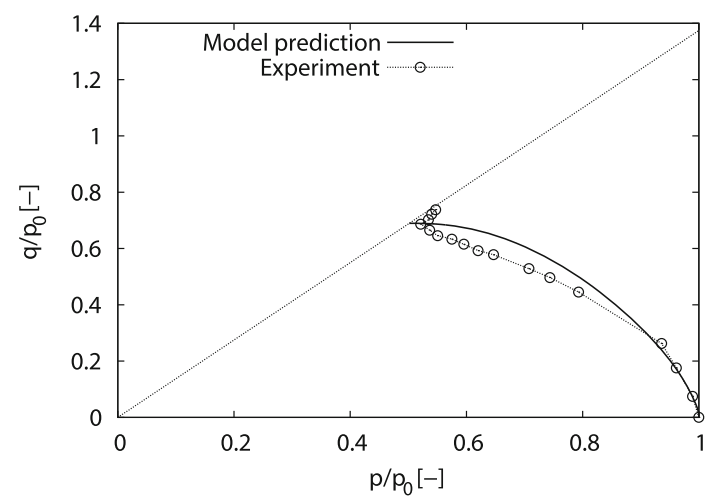

(b)

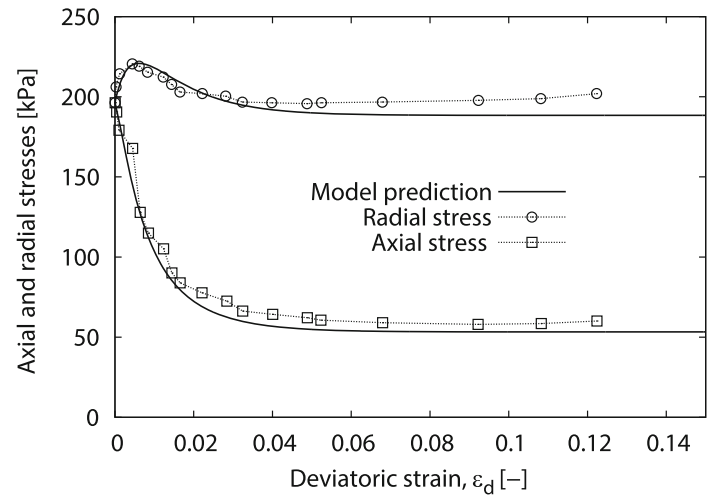

(c)

Fig. 4 Comparison between experimental and numerical undrained triaxial tests on normally consolidated Fujinomory clay. Experimental data from Nakai and Mihara [21]

the prediction of unloading lines is achieved in the simulations.

Note that an unloading index, e.g., $\kappa^{*}$, is used in most of the existing hypoplastic clay models $[11,16,19]$. It can be expected that the inclusion of an unloading index will facilitate the numerical modeling for one cycle of unloading, while it has little contribution in capturing the cyclic behavior with a large number of loading cycles [38]. In contrast, the numerical result indicates that, although the unloading index is not included in this model, a reasonable 


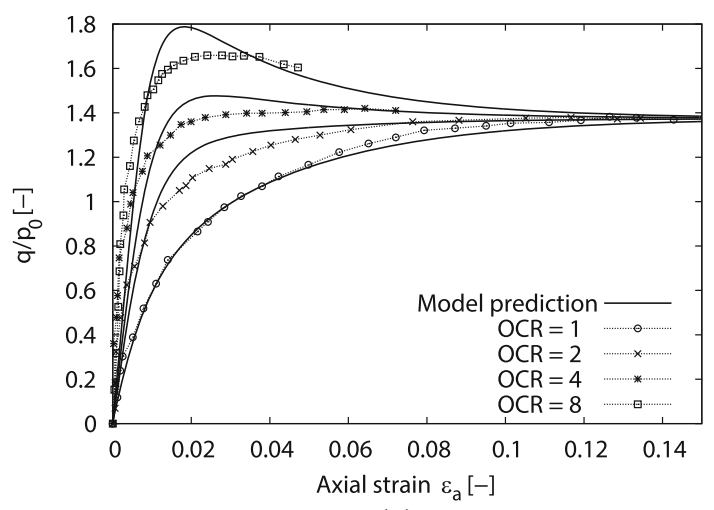

(a)

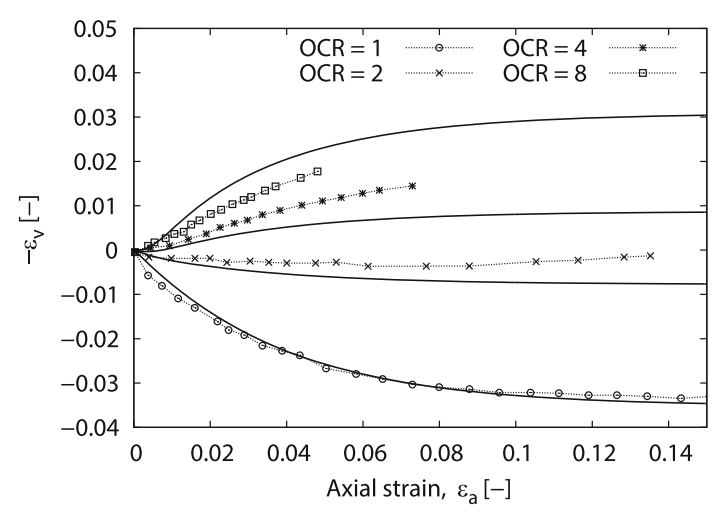

(b)

Fig. 5 Comparison between experimental and numerical drained triaxial tests with constant $p$ on OC Fujinomory clay. Experimental data from Nakai et al. [22]

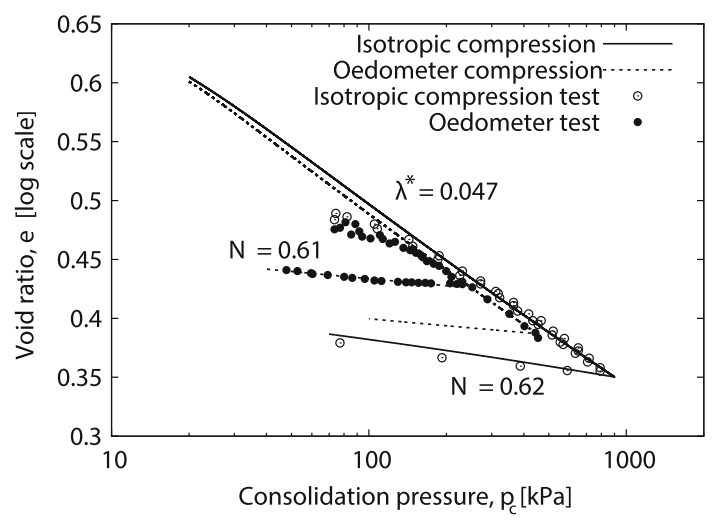

Fig. 6 Comparison between experiments and predicted isotropic and oedometer compression tests. Experimental data from Pestana et al. [29]

unloading behavior can be predicted by this model. This property is significantly different from most elastoplastic models developed in the framework of MCC, in which the elastic behaviors are solely controlled by the unloading index. In the proposed hypoplastic model, however, there is not a clear boundary between the elastic and the plastic deformation. Therefore, it is not necessary to include the unloading index for a hypoplastic clay model.

We now turn our attention to the prediction of overconsolidation behavior in drained compression tests. Figure 7 compares the model predictions with experimental results from a series of drained triaxial compression tests on isotropically consolidated specimens with different OCRs. As the OCR increases, the behavior changes from contractive to nearly neutral to dilative at higher OCRs (e.g., OCR = 10). Generally, the shear stress-strain response and volumetric behavior are very well described by the proposed model although the model slightly overestimates the measured dilation and contraction at heavily consolidated condition $(\mathrm{OCR}=10)$ and normally consolidated condition $(\mathrm{OCR}=1)$, respectively. Overall, the overconsolidation behavior predicted by the model is in excellent agreement with experimental data.

\subsection{Boston blue clay}

Finally, we consider the capability of the proposed model in describing undrained response of OC clays. Several simulations of undrained triaxial compression tests on

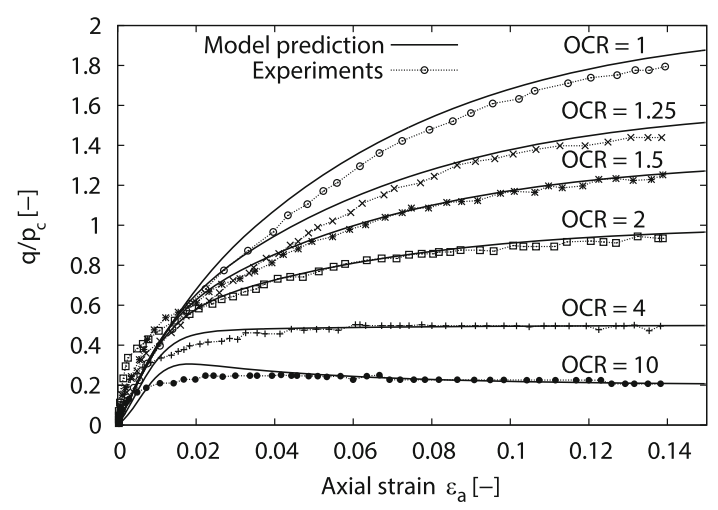

(a)

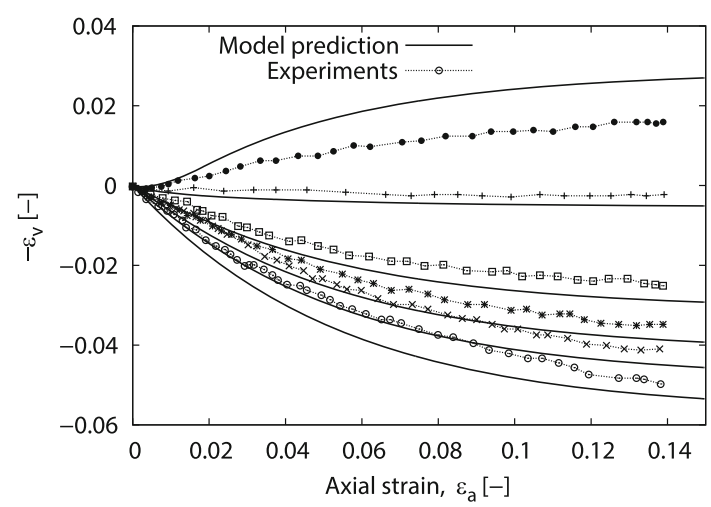

(b)

Fig. 7 Comparison between experimental and numerical drained constant $p$ triaxial tests on OC Lower Cromer Till. Experimental data from Pestana et al. [29] 
Boston blue clay are carried out. The specimens were isotropically consolidated to reach different initial overconsolidation ratios. The initial void ratio used in the simulations are $e_{0}=0.918,0.93,0.94$, and 0.95 for OCR $=$ $1,2,4$, and 8 , respectively. The model parameters are listed in Table 1.

Figure 8 compares the predictions of stress paths for undrained triaxial compression tests with experimental results. The experiment at OCR $=8$ is not provided in the literature [29], and thus it is not considered in the simulation of strain-stress simulation. Generally, the model gives excellent predictions of the deviatoric stresses and stress paths for all OCRs. A slight difference in the stress path is observed for OCR $=2$. This less good result may be attributed to the model that underestimates the stiffness response at higher strains, thereby leading to a higher shear-induced pore pressures.

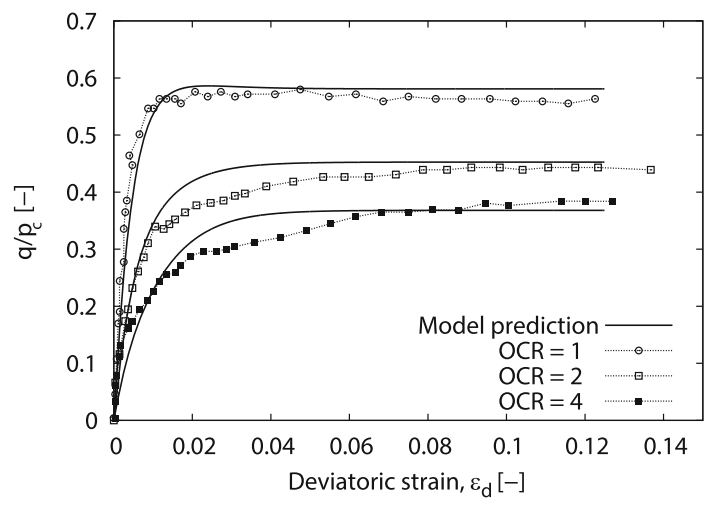

(a)

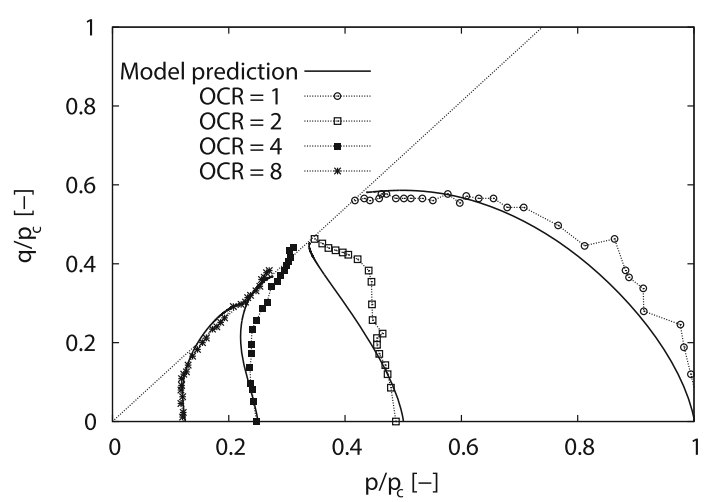

(b)

Fig. 8 Comparison between experimental and numerical undrained triaxial tests on OC Boston Blue Clay. Experimental data from Pestana et al. [29]

\section{Conclusions}

Consolidation history is one of the most important factors that affect the mechanical behaviors of OC clays. However, hypoplastic constitutive models that describe, in a quantitative manner, the stress-strain and deformation behaviors of clays are relatively rare compared with the well-developed frameworks for sands. A general framework of hypoplasticity including a structure tensor for history dependence is proposed in our recent paper [38]. In the present paper, calibration and validation of a basic hypoplastic model for sand are carried out to allow this model to describe the overconsolidation behavior of clays.

In comparison with the MCC model, our model possesses simpler formulations and better performance particularly for OC clays. Whereas the MCC model captures properly the salient features of clay with normal consolidation, it shows large elastic region, sudden transition from elastic into plastic region, as well as poor predictions of peak failure stresses and dilatancy for clays with heavy overconsolidation. Purely elastic behavior within the yield surface makes the MCC model inadequate for OC clays. Our model remedies these shortcomings. Numerical predictions show that it is able to properly describe the main behaviors of OC clays, such as strain softening and volumetric expansion under the drained condition, as well as the evolution of undrained shear strength and excess pore pressure during the undrained shearing process.

The model requires only five material parameters. All the parameters except $\alpha$ have clear physical meaning and can be easily determined from conventional laboratory tests. Although a swelling index is not adopted in our model, a reasonable unloading behavior can be reproduced. This feature makes our model simpler than the existing hypoplastic models for clays $[11,16,19]$. Therefore, it is an ideal basic version to build more sophisticated models for predicting behaviors of clays under, e.g., partially saturated and thermal conditions. Moreover, numerical implementation of the model is also quite straightforward even with the Matsuoka-Nakai failure criterion, and hence it is particularly suitable for practical applications.

Acknowledgements The study was financially supported by the H2020 Marie Skłodowska-Curie Actions RISE 2017 HERCULES (778360) and FRAMED (734485); the Erasmus+ KA2 Project Rebuilt (2018-1-RO01-KA203-049214); and the Nazarbayev University Research Fund (SOE2017001). The first author wishes to thank the Otto Pregl Foundation for financial support in Austria.

Open Access This article is licensed under a Creative Commons Attribution 4.0 International License, which permits use, sharing, adaptation, distribution and reproduction in any medium or format, as long as you give appropriate credit to the original author(s) and the source, provide a link to the Creative Commons licence, and indicate if changes were made. The images or other third party material in this 
article are included in the article's Creative Commons licence, unless indicated otherwise in a credit line to the material. If material is not included in the article's Creative Commons licence and your intended use is not permitted by statutory regulation or exceeds the permitted use, you will need to obtain permission directly from the copyright holder. To view a copy of this licence, visit http://creativecommons. org/licenses/by/4.0/.

Funding Open access funding provided by University of Natural Resources and Life Sciences Vienna (BOKU).

\section{Appendix}

The proposed model is formulated as follows:

$$
\begin{aligned}
\stackrel{\circ}{\mathbf{T}}= & f_{s}\left[(\operatorname{tr} \check{\mathbf{T}}) \mathbf{D}+f_{v}(\operatorname{tr} \mathbf{D}) \check{\mathbf{T}}+a^{2} \frac{\operatorname{tr}(\check{\mathbf{T}} \mathbf{D})}{\operatorname{tr} \check{\mathbf{T}}} \check{\mathbf{T}}\right. \\
& \left.+f_{u} a\left(\hat{\mathbf{T}}+\hat{\mathbf{T}}^{*}\right)\|\mathbf{D}\|\right]
\end{aligned}
$$

where $\check{\mathbf{T}}=\mathbf{T}+\mathbf{S}$ and $\hat{\mathbf{T}}=\mathbf{T}-\mathbf{S}$ with $\mathbf{S}$ denoting the structure tensor for overconsolidation. It is expressed as follows:

$\mathbf{S}=\alpha \ln \left(\frac{1}{R}\right) \mathbf{T}$

in which $R$ stands for the degree of overconsolidation:

$R=\left(p+\frac{q^{2}}{M^{2} p}\right) \exp \left[\frac{\ln (1+e)-N}{\lambda^{*}}\right] \quad(0<R \leqslant 1)$

The stiffness factor $f_{s}$ and the multipliers $f_{v}$ and $f_{u}$ are defined as follows:

$f_{s}=-\frac{2}{3 v_{i} \lambda^{*}}, f_{v}=\frac{3}{2} v_{i}-\frac{1}{3}\left(3+a^{2}-\sqrt{3} a\right), f_{u}=\frac{\|\mathbf{B}: \mathbf{D}\|}{\|\mathbf{B}\|\|\mathbf{D}\|}$

where $\mathbf{B}$ denotes the flow rule of the model.

In the above equations, $a$ and $M$ correspond to the limit stress at critical state, giving

$a=\frac{\sqrt{3} \eta\left(3-\sin \phi_{c}\right)}{2 \sqrt{2} \sin \phi_{c}}$, and $M=\frac{6 \sin \phi_{c}}{\eta\left(3-\sin \phi_{c}\right)}$

where the factor $\eta$ is adopted to incorporate the MatsuokaNakai failure criterion, to give

$$
\eta=\frac{2 I_{1}}{3 \sqrt{\left(I_{1} I_{2}-I_{3}\right)\left(I_{1}^{2}-3 I_{2}\right) /\left(1_{1} I_{2}-9 I_{3}\right)}-\sqrt{\left(I_{1}^{2}-3 I_{2}\right)}}
$$

in which $I_{1}, I_{2}$, and $I_{3}$ are stress invariants:

$I_{1}=\operatorname{tr} \mathbf{T}, \quad I_{2}=0.5\left[\mathbf{T}: \mathbf{T}-\left(I_{1}\right)^{2}\right], \quad I_{3}=\operatorname{det} \mathbf{T}$

$\operatorname{det} \mathbf{T}$ is the determinant of $\mathbf{T}$.
There are five parameters for the proposed model: $\phi_{c}, v_{i}$, $\lambda^{*}, N$, and $\alpha . \phi_{c}$ is the critical state friction angle; $v_{i}$ is the ratio of the bulk modulus in the isotropic compression and the shear modulus in the undrained shear test on the isotropic consolidated sample; $\lambda^{*}$ is the slope of the isotropic normal compression line in the double logarithmic plane $\ln (1+e)-\ln p ; N$ is the value of $\ln (1+e)$ at the isotropic normal compression line for $p_{r}=1 \mathrm{kPa}$; and $\alpha$ controls the magnitude of the structure tensor.

\section{References}

1. Asaoka A, Nakano M, Noda T (2000) Superloading yield surface concept for highly structured soil behavior. Soils Found 40(2):99-110

2. Bauer E (1996) Calibration of a comprehensive hypoplastic model for granular materials. Soils Found 36(1):13-26

3. Butterfield R (1979) A natural compression law for soils (an advance on $\left.e-\log p^{\prime}\right)$. Géotechnique 29(4):24-43

4. Dafalias YF, Herrmann LR (1986) Bounding surface plasticity. II: application to isotropic cohesive soils. J Eng Mech 112(12):1263-1291

5. Das A, Bajpai PK (2018) A hypoplastic approach for evaluating railway ballast degradation. Acta Geotech 13:1085-1102. https:// doi.org/10.1007/s11440-017-0584-7

6. Fuentes W, Tafili M, Triantafyllidis T (2017) An ISA-plasticitybased model for viscous and non-viscous clays. Acta Geotechnica. https://doi.org/10.1007/s11440-017-0548-y

7. Fuentes W, Wichtmann T, Gil M, Lascarro C (2019) ISA-Hypoplasticity accounting for cyclic mobility effects for liquefaction analysis. Acta Geotechnica. https://doi.org/10.1007/s11440-01900846-2

8. Gao ZW, Zhao JD, Yin ZY (2016) Dilatancy relation for overconsolidated clay. Int J Geomech 17(5):06016035

9. Hashiguchi K (1989) Subloading surface model in unconventional plasticity. Int J Solids Struct 25(8):917-945

10. Herle I, Kolymbas D (2004) Hypoplasticity for soils with low friction angles. Comput Geotech 31(5):365-373

11. Huang WX, Wu W, Sun DA, Sloan S (2006) A simple hypoplastic model for normally consolidated clay. Acta Geotech 1(1):15-27

12. Jocković S, Vukićević M (2017) Bounding surface model for overconsolidated clays with new state parameter formulation of hardening rule. Comput Geotech 83:16-29

13. Li XS, Dafalias YF (2011) Anisotropic critical state theory: role of fabric. J Eng Mech 138(3):263-275

14. Lu DC, Liang JY, Du XL, Ma C, Gao ZW (2019) Fractional elastoplastic constitutive model for soils based on a novel 3D fractional plastic flow rule. Comput Geotech 105:277-290

15. Lin J, Wu W, Borja RI (2015) Micropolar hypoplasticity for persistent shear band in heterogeneous granular materials. Comput Methods Appl Mech Eng 289(1):24-43

16. Mašín D (2005) A hypoplastic constitutive model for clays. Int J Numer Anal Meth Geomech 29(4):311-336

17. Mašín D, Herle I (2007) Improvement of a hypoplastic model to predict clay behavior under undrained conditions. Acta Geotech 2(4):261

18. Mašín D (2012) Hypoplastic Cam-Clay model. Géotechnique 62(6):549-553

19. Mašín D (2013) Clay hypoplasticity with explicitly defined asymptotic states. Acta Geotech 8(5):481-496 
20. Mcdowell GR, Hau KW (2004) A generalised modified Cam Clay model for clay and sand incorporating kinematic hardening and bounding surface plasticity. Granular Matter 6(1):11-16

21. Nakai T, Mihara Y (1984) A new mechanical quantity for soils and its application to elastoplastic constitutive models. Soils Found 24(2):82-94

22. Nakai T, Matsuoka H, Okuno N, Tsuzuki K (1986) True triaxial tests on normally consolidated clay and analysis of the observed shear behavior using elastoplastic constitutive models. Soils Found 26(4):67-78

23. Nakai T, Hinokio M (2004) A simple elastoplastic model for normally and over consolidated soils with unified material parameters. Soils Found 44(2):53-70

24. Niemunis A (2003) Extended hypoplastic models for soils. Habilitation Thesis, Ruhr-University, Bochum

25. Pender MJ (1978) A model for the behavior of overconsolidated soil. Géotechnique 28(1):1-25

26. Peng C, Wu W, Yu HS, Wang C (2015) A SPH approach for large deformation analysis with hypoplastic constitutive model. Acta Geotech 10(6):703-717. https://doi.org/10.1007/s11440015-0399-3

27. Peng C, Guo XG, Wu W, Wang YQ (2016) Unified modeling of granular media with smoothed particle hydrodynamics. Acta Geotech 11(6):1231-1247. https://doi.org/10.1007/s11440-0160496-y

28. Peng C, Wang S, Wu W, Yu HS, Wang C, Chen J (2019) LOQUAT: an open-source GPU-accelerated SPH solver for geotechnical modeling. Acta Geotech 14(5):1269-1287

29. Pestana JM, Whittle AJ, Gens A (2002) Evaluation of a constitutive model for clays and sands: Part II-clay behavior. Int J Numer Anal Meth Geomech 26(11):1123-1146

30. Porcino DD, Diano V, Triantafyllidis T, Wichtmann T (2019) Predicting undrained static response of sand with non-plastic fines in terms of equivalent granular state parameter. Acta Geotechnica. https://doi.org/10.1007/s11440-019-00770-5

31. Roscoe KH and Burland JB (1968) On the generalized stressstrain behavior of 'wet' clay. In: Proceedings of symposium on engineering plasticity. Cambridge, pp 535-610

32. Schofield A, Wroth P (1968) Critical state soil mechanics, vol 310. McGraw-Hill, London

33. Shi XS, Herle I, Bergholz K (2017) A nonlinear Hvorslev surface for highly OC clays: elastoplastic and hypoplastic implementations. Acta Geotech 12(4):809-823

34. Tafili M, Triantafyllidis T (2020) AVISA: anisotropic visco-ISA model and its performance at cyclic loading. Acta Geotechnica. https://doi.org/10.1007/s11440-020-00925-9

35. Tang Y, Wu W, Yin KL, Wang S, Lei GP (2019) A hydromechanical coupled analysis of rainfall induced landslide using a hypoplastic constitutive model. Comput Geotech 112:284-292
36. Wang S, Wu W, He PC, Cui DS (2018) Numerical integration and FE implementation of a hypoplastic constitutive model. Acta Geotech 13(6):1265-1281

37. Wang S, Wu W, Yin ZY, Peng C, He XZ (2018) Modeling the time-dependent behavior of granular material with hypoplasticity. Int J Numer Anal Meth Geomech 42(12):1331-1345

38. Wang S, Wu W (2020) A simple hypoplastic model for overconsolidated clays. Acta Geotechnica. https://doi.org/10.1007/ s11440-020-01000-z

39. Wang S, Wu W, Zhang DC, Kim JR (2020) Extension of a basic hypoplastic model for overconsolidated clays. Comput Geotech. https://doi.org/10.1016/j.compgeo.2020.103486

40. Wu W, Kolymbas D (1990) Numerical testing of the stability criterion for hypoplastic constitutive equations. Mech Mater 9(3):245-253

41. Wu W, Bauer E (1994) A simple hypoplastic constitutive model for sand. Int J Numer Anal Meth Geomech 18(12):833-862

42. Wu W, Bauer E, Kolymbas D (1996) Hypoplastic constitutive model with critical state for granular materials. Mech Mater 23(1):45-69

43. Wu W, Niemunis A (1997) Beyond failure in granular materials. Int J Numer Anal Methods Geomech 21:153

44. Wu W, Lin J, Wang XT (2017) A basic hypoplastic constitutive model for sand. Acta Geotech 12(6):1373-1382

45. Wu W, Wang S, Xu GF, Qi JL, Zhang DC, Kim JR (2019) Numerical simulation of a caes pile with hypoplasticity. In: Desiderata Geotechnica, pp 242-249. Springer

46. Yao YP, Lu DC, Zhou AN, Zou B (2004) Generalized nonlinear strength theory and transformed stress space. China Ser E Technol Sci 47(6):691-709

47. Yao YP, Hou W, Zhou AN (2009) UH model: three-dimensional unified hardening model for overconsolidated clays. Géotechnique 59(5):451-469

48. Yao YP, Zhou AN (2013) Non-isothermal unified hardening model: a thermo-elasto-plastic model for clays. Géotechnique 63(15):1328-1345. https://doi.org/10.1680/geot.13.p.035

49. Yin ZY, Chang CS (2009) Non-uniqueness of critical state line in compression and extension conditions. Int $\mathbf{J}$ Numer Anal Meth Geomech 33(10):1315-1338

50. Yin ZY, Jin YF, Shen SL, Huang HW (2017) An efficient optimization method for identifying parameters of soft structured clay by an enhanced genetic algorithm and elasticviscoplastic model. Acta Geotech 12(4):849-867

51. Yin ZY, Jin YF, Shen SL, Hicher PY (2018) Optimization techniques for identifying soil parameters in geotechnical engineering: Comparative study and enhancement. Int J Numer Anal Meth Geomech 42(1):70-94

Publisher's Note Springer Nature remains neutral with regard to jurisdictional claims in published maps and institutional affiliations. 